\title{
Desconsolidación de la democracia: retos contemporáneos y reflexiones para salvar nuestros Estados
}

\author{
Desconsolidation of Democracy: Contemporary \\ challenges and reflections to save our States
}

Reseña del libro: El pueblo contra la democracia: por qué nuestra libertad está en peligro y cómo salvarla

Yascha Mounk (2018). $1^{a}$ Edición. Barcelona, España: Editorial Paidós

Camila Valencia Galarza *
Investigadora Jurídica Independiente

Información del Artículo

Original - Ruptura, 2020

Artículo recibido / Received: 15 de octubre, 2020

Artículo aceptado / Accepted: 03 de diciembre, 2020

\section{Citación}

Valencia, C. (2020). Desconsolidación de la democracia: retos contemporáneos y reflexiones para salvar nuestros Estados. Reseña del libro: El pueblo contra la democracia: por qué nuestra libertad en peligro y como salvarla. Revista Ruptura de la Asociación Escuela de Derecho PUCE. Edición 2020, p (623-645).

DOI: $10.26807 /$ rr.vi02.59

Resumen: En el presente trabajo se realizará una reseña del libro "El pueblo contra la democracia: Por qué nuestra libertad está en peligro y cómo salvarla" de Yascha Mounk. En primer lugar, se describirá el

* Egresada de la carrera de Derecho por la Universidad de Cuenca, Ecuador. Correo electrónico: camila.valencia.ge@gmail.com 
problema de investigación que ha identificado el autor; para luego abordar someramente cada capítulo, haciendo énfasis en las ideas fundamentales que se encuentran a lo largo del texto. A su vez, se emite una crítica con respecto a ciertas posturas que deben ser puestas al debate. Finalmente, se emitirán las conclusiones a las que ha llegado el autor y lo que ha buscado transmitir con su libro, sin dejar de lado consideraciones personales acerca del tema, principalmente, abordado por el autor: la democracia liberal; institución jurídica relevante para el Derecho.

Palabras clave: Democracia liberal, democracia iliberal, liberalismo no democrático y populismo.

Abstract: In this work, a review of the book "The People vs. Democracy" by Yascha Mounk will be made. In the first place, will be described the research problem identified by the author; and then briefly address each chapter, emphasizing the fundamental ideas found throughout the text. At the same time, is issued criticism regarding certain positions that should be put to debate. Finally, the conclusions reached by the author and what he has sought to convey throughout his book will be issued-without neglecting personal considerations about the subject- mainly approached by the author: the liberal democracy: legal institution relevant to Law.

Key words: Liberal democracy, illiberal democracy, undemocratic liberalism, and populism.

\section{Introducción}

Desde antaño, el término democracia se ha utilizado en las distintas naciones y no ha habido acuerdo alguno en cuanto a su significado, tanto es así que incluso varios doctrinarios consideran que se trata de un concepto jurídico indeterminado. Para Mounk (2018), la democracia es "un conjunto de instituciones electorales vinculantes que traducen de manera efectiva las opiniones populares en unas políticas públicas concretas" (p. 33). Es importante considerar esta definición ya que esta es la base para entender las posturas que se abordan a lo largo del texto. 
Según Yascha Mounk (en adelante el autor), la democracia -en sí- no es suficiente para la consolidación de un Estado, siendo menester considerar su combinación con el liberalismo. Sin embargo, en este punto, nuevamente nos encontramos frente a un término que puede provocar confusión; por esa razón Mounk (2018) define al liberalismo como aquello que permite la materialización de los derechos individuales, así supone la existencia de una correlación entre libertad e igualdad.

A partir de estos dos conceptos, el autor aborda el tema central de su libro: la democracia liberal. La considera como aquella mezcla única entre la manifestación de la voluntad popular -gobierno popular- y los derechos individuales (Mounk, 2018). Esta institución jurídica se desarrolla a lo largo de tres capítulos, haciendo énfasis en problemáticas en las que, actualmente, se ven inmersos distintos países $^{1}$ debido a contrariedades estructurales, políticas, sociales y económicas; factores que traen consigo que la democracia se encuentre en inminente peligro.

Entonces, ¿puede una democracia desconsolidarse?, y de ser así, ¿es posible salvarla de su desconsolidación? Si bien se considera inimaginable que la democracia -institución fuertemente desarrollada a lo largo del tiempo- pueda desprenderse, la realidad que nos atañe es otra. En las últimas décadas hay más personas que se inclinan hacia un gobierno dirigido por "hombres fuertes" o se sienten seducidos por la idea de uno autoritario (Mounk, 2018).

El autor desarrolla la siguiente premisa: sí es posible que las democracias se desconsoliden y que, de hecho, eso puede estar pasando en la actualidad. Estas fuertes alegaciones que hace el autor son confirmadas mediante encuestas que ha realizado para dar solidez a su investigación, por lo que, teniendo en cuenta esta gran problemática,

1 Yascha Mounk a lo largo de su texto analiza principalmente la realidad política de países pertenecientes a América del Norte y Europa Occidental. A pesar de que su investigación se centra en los territorios mencionados, no hay que desmerecer las reflexiones interesantes y, sobre todo, trascendentales que podrían aplicarse a todos los países, teniendo en cuenta los matices propios de cada nación. 
se ve inmerso en describir el origen de esta para, consecutivamente, exponer sus posibles remedios.

Las reflexiones que se encuentran en este texto se vuelven fundamentales para el Derecho, pues explican la forma en la cual fuertes partidos políticos populistas, así como diversos factores estructurales y tecnológicos están socavando la democracia liberal, además, presenta cómo esto afecta a los derechos individuales o a la voluntad popular -a pesar de haber sido considerada más o menos estable e, incluso, consolidada una vez culminada la Segunda Guerra Mundial-. Si bien es cierto que el autor aborda una metodología bastante descriptiva y experimental enfocándose únicamente en el marco de países pertenecientes a América del Norte y Europa Occidental no deja de ser menos importante el hecho de que sus reflexiones puedan ser aplicadas -evidentemente, con ciertos matices- en países pertenecientes a Latinoamérica y, en concreto, en nuestro país, Ecuador.

\section{Capítulo I: La crisis de la democracia liberal}

\subsection{Democracia sin derechos}

La democracia sin derechos -o también llamada "democracia iliberal"- trae consigo un debate acerca de cómo los partidos políticos populistas inician seduciendo al pueblo con la idea de que su voz nunca más será callada para terminar, de esta forma, acaparando instituciones democráticas hasta el punto en que los derechos individuales se vean seriamente comprometidos, surgiendo así el inminente peligro de la consolidación de un gobierno autoritario.

Para comprender el problema, el autor trata de explicar el riesgo que acarrea que el poder se encuentre en manos de populistas, incluso exterioriza lo que perpetran para mantenerse en este. Para ello, analiza la campaña llevada a cabo por Donald Trump en las elecciones presidenciales de Estados Unidos de Norteamérica en 2016. Trump llegó al poder de manera "inesperada” según muchos politólogos, pues es difícil de creer que alguien con ideales tan extremis- 
tas pueda ganar las elecciones de un país que hace honor a valores fundamentales como la libertad. Lo cierto es que Trump pudo ganar las elecciones porque su perfil era el de un populista, pues le vendía al pueblo estadounidense soluciones simplistas y fáciles a los problemas que le atañen al país como lo hizo, por ejemplo, respecto a la inmigración y su solución de construir un muro en la frontera con México (Mounk, 2018). Estas posturas que pecan de simplismo propenden al populismo porque llegan de forma tentadora a aquella parte de la población que mantiene constructos sociales y raciales, conllevando a que estos crezcan aún más, cuando se supone que en la actualidad se intenta prescindir de posturas discriminatorias.

No obstante, el problema se desarrolla cuando estas soluciones no funcionan y el pueblo, llevado por ideales ya inculcados, buscan otro populista que sí las materialice. Desde otra perspectiva, en caso de que estas soluciones efectivamente se cumplan, pueden traer como consecuencia una dictadura (Mounk, 2018). En sí, "los populistas moldean la identidad de la mayoría traicionada y de la minoría despreciada a medida que lo necesita según su contexto local, la estructura retórica de la que se valen es llamativamente parecida en cualquier parte del mundo" (Mounk, 2018, p.46).

Otro rasgo fundamental que el autor identificó como rasgo característico de un populista es que el político empieza con enunciados tales como "el pueblo decide y yo soy vuestra voz" (Mounk, 2018, p.47). En este punto, el populista introduce una idea en la mente de los votantes: existe un pueblo que es real, formado por aquellos que comparten ciertos rasgos culturales, étnicos o religiosos, dejando a lado minorías que se alejan de dicho escenario. Por consiguiente, se difunde la creencia de que la mayoría manda, quien habla por ellos es el político, por lo tanto, no hay nada más importante que la voluntad popular (Mounk, 2018).

Una vez alcanzado el poder, el populista redirecciona sus energías hacía el pueblo para que este tenga la convicción de que ciertas "instituciones formales o informales osan de disputar sus pretensiones de monopolio moral de la representación" (Mounk, 2018, 48). Esto implica el acaparamiento de aquellas instituciones democráticas que garantizan derechos individuales. Cuando se alcanza este objetivo, 
efectivamente se ha caído en una dictadura; el elemento democrático con el cual inició el populista queda totalmente perdido.

Observando otra perspectiva, hay analistas destacados como Jan-Werner Müller, que están en contra del carácter democrático del populismo, así como del término "democracia iliberal". Este autor considera que dicha expresión solamente legitima los actos antidemocráticos de los populistas, que por cuestión lógica, estos no tienen naturaleza democrática (Müller, 2016).

Regresando al pensamiento de Mounk (2018) este hace especial énfasis en que, como se manifestó anteriormente, el populismo no es del todo antidemocrático, es decir, su naturaleza tiene un tinte democrático e iliberal. Desde un inicio lo que se busca -o al menos lo que se propaga- es que la voluntad popular sea un valor fundamental. Sin embargo, posteriormente, ese valor se ve socavado por el ansia del político de acaparar todo el poder pasando por alto la voluntad popular que tanto profesó. El no entender esto, menciona Mounk (2018), hace que muchos no podamos comprender que este problema tiene un carácter atractivo (componente democrático) el mismo que, si lo excluimos del panorama solamente dificulta las posibilidades de descubrir cómo frenarlo.

\subsection{Derechos sin democracia}

¿Cuándo garantizar derechos individuales puede llevarnos a un Estado no democrático? Dentro de este contexto, surge el término "derechos sin democracia". Los derechos individuales se han materializado, pero esto ha provocado que la voluntad popular se vea disminuida e, incluso, que muchos ciudadanos no se sientan partícipes en las decisiones que toman los gobernantes (Mounk, 2018).

El ideal de la democracia directa ha quedado atrás ya sea por circunstancias geográficas, sociales, económicas y políticas que han provocado su transformación. De esta manera, se consolidó una democracia representativa, en la cual, debido a la creación y división 
de los poderes del Estado, la máxima expresión del pueblo se confió al órgano legislativo.

Entonces, surge la siguiente interrogante: ¿es legítimo que otros órganos desarrollen actividades legislativas? El camino hacia esta respuesta trae a colación un debate que se ha desarrollado a lo largo del tiempo. Hay quienes consideran que las decisiones de otras instituciones en el ejercicio de facultades legislativas pueden estar alejadas de la voluntad del pueblo, ya que no son tomadas en el desenvolvimiento de un debate político.

Como, por ejemplo, los servidores de la administración pública muchas veces han sido llamados "burócratas legisladores" debido a que la finalidad de que sea la voluntad popular la que legisle va encaminada a que las instituciones que apliquen estas normas estén subordinadas por dicha voluntad. Es decir, no cabría un margen de arbitrariedad y discrecionalidad de estos funcionarios (Mounk, 2018). No obstante, la realidad es otra. Ninguna ley va a ser lo suficientemente completa para regular todas las conductas posibles, ya que la norma siempre es finita, por otra, los hechos infinitos.

Esta dificultad da paso a que muchos Estados doten de atribuciones legislativas a sus administradores con la finalidad de solventar futuras anomias; o que la regulación sobre ciertas cuestiones técnicas caiga en órganos especializados al respecto. El autor se encamina en la importancia que tiene la realización de funciones por parte de ciertas instituciones que no puede -con facilidad- efectuar el órgano legislativo, pero no prescinde la preocupación de que cada vez estas facultades legislativas son más amplias, acarreando que varios asuntos sean suprimidos del debate político (Mounk, 2018).

Siguiendo la misma línea, el surgimiento del control judicial de constitucionalidad ha dado origen a posturas que explican que este control es antidemocrático porque es efectuado por un grupo de jueces que no ostentan legitimidad y por no haber sido elegidos popularmente. Jeremy Waldron (1998) critica este control y sostiene la importancia de que temas polémicos no sean desprovistos del debate político porque puede traer como resultado la falta de consenso social 
sobre cuestiones que tienen una fuerte carga moral donde las personas tienen posiciones tajantes; verbigracia, como lo es: el aborto.

Empero, el autor, si bien tiene en cuenta todas estas críticas sobre el carácter antidemocrático del mencionado control, manifiesta su apoyo a los fundamentos esbozados por autores como Dworkin y Kelsen que están a favor de la legitimidad de los jueces para efectuar un control de constitucionalidad. Estos autores sostienen que, a pesar de existir la supresión del debate político en temas que las personas tienen opiniones fuertemente controvertidas, es necesario que los jueces hagan un análisis constitucional en los diferentes casos para proteger derechos individuales de minorías que, en ocasiones, son invisibilizadas; y así, en momentos de crisis, tales como en el caso de gobiernos de "hombres fuertes", estas no se vean desprotegidas (Mounk, 2018).

Considero que el control de constitucionalidad que ejerce el poder judicial, o en algunos países -como en el nuestro- la Corte Constitucional, no propende a la eliminación del debate político. Todo lo contrario. El control que ejercen estos jueces da paso a que las decisiones tomadas por organismos técnicos de la administración pública sean explicadas de mejor forma, sin tecnicismos, permitiendo que los ciudadanos comprendan de mejor manera. De hecho, da paso a que estos funcionarios se vean obligados a emitir una mayor motivación, respecto del apego que sus decisiones deban -en palabras de Kelsen- a la norma fundamental (Uprimny, 2001). Retórica que se hace posible sólo al momento en que ejercen su defensa ante jueces constitucionales.

No obstante, pese a estar de acuerdo con la legitimidad y conveniencia del control de constitucionalidad por parte de jueces constitucionales ${ }^{2}$, opino que dicha cuestión ha abierto la puerta para que

2 Me refiero a jueces constitucionales porque, como se mencionó anteriormente, en la realidad ecuatoriana, estos son los encargados de realizar el control de constitucionalidad de aquellas decisiones que emanen los órganos que ostentan facultades legislativas. 
este órgano independiente de la función judicial realice funciones cada vez más amplias, y de ser así, resulta claro que se estaría vulnerando normas democráticas básicas ${ }^{3}$. Por ejemplo, en la Sentencia N024-16-SIN-CC la Corte Constitucional resolvió una acción pública de inconstitucionalidad de una ordenanza dictada por el Consejo Cantonal del GAD Limón Indanza. Entonces, estamos frente al escenario de un órgano que es representante del pueblo y a quien se le ha confiado facultades legislativas en aras de satisfacer necesidades básicas de aquellas personas que conforman una circunscripción territorial. La Corte determinó que la ordenanza fue en contra de normas constitucionales que tutelan los derechos de las personas discapacitadas frente a los tributos, pero la sentencia no termina ahí. Los jueces constitucionales legislaron el pasaje de la ordenanza considerando que vulneraba derechos fundamentales (Patricio Peláez y Otros vs. GAD Municipal Limón Indanza, Sentencia No. 024-16-SINCC, 2016). De esta forma nace la interrogante ¿es legítimo que la Corte Constitucional se atribuya actividades legislativas? Pregunta que, en nuestra realidad ecuatoriana, no ha encontrado respuesta firme constituyendo un debate desde que inició la justicia constitucional ${ }^{4}$.

Prosiguiendo con el análisis, después de la fuerte experiencia que nos dejó la Segunda Guerra Mundial, se dio origen a la creación de organismos y tratados internacionales con la finalidad de fortalecer la cooperación internacional, evitar conflictos bélicos y propender a la globalización. El autor considera que esto ha traído ciertos beneficios. Un claro ejemplo es en el ámbito del cambio climático, para combatirlo se requiere el trabajo y compromiso de varios países. No obstante, realiza una observación en cuanto a que cada vez estos organismos están

3 Acerca del debate sobre la dificultad contramayoritaria y antidemocrática del control judicial de constitucionalidad, véase: Gargarella, R. (1996). La justicia frente al gobierno: sobre el carácter contramayoritario del poder judicial. Barcelona, España: Ariel.

4 Acerca del debate de si es o no legítimo y conveniente que las Cortes Constitucionales realicen el control de constitucionalidad, véase: Uprimny, R. (2001). Legitimidad y conveniencia del control constitucional de la economía. Precedente Revista Jurídica, (-) 35-66. DOI: 10.18046/prec.v0.1382 
carcomiendo la independencia de los Estados, como en el caso de los tratados de libre comercio, que, a pesar de sus ventajas, ocasionan cierta inhabilitación a los Estados miembros para gravar con aranceles, lo cual compromete su libertad de maniobra (Mounk, 2018).

\subsection{La democracia se está desconsolidando}

El autor, al realizar su investigación, efectuó estudios estadísticos a cierta población estadounidense, los cuales muestran que gran parte de los encuestados nacidos en las décadas de 1930 y 1940 consideran que es esencial vivir en una democracia. No obstante, aquellos nacidos después de 1980 creen que no es fundamental (Mounk, 2018). Estos datos han sorprendido a muchos politólogos, aunque Mounk (2018) cree que tiene que ver con el componente histórico: los abuelos de los millennials han vivido la época dura de la guerra, por ello conocen y saben la importancia de tener una democracia consolidada. Igualmente, están conscientes que la misma no llega a su fin, como en el caso de Polonia y Venezuela. Desde otro punto de vista, los relativamente jóvenes sienten que sus intereses están cada vez menos representados por los políticos que tienden al conservadurismo y por eso le dan escasa o nula importancia al hecho de vivir en una democracia (Mounk,2018).

Asimismo, el autor a través de encuestas llegó a la conclusión de que el $24 \%$ de estadounidenses de todas las edades apoyaban la idea de un líder fuerte, aquel que pase por encima del órgano legislativo y de las elecciones. En el 2018, ese porcentaje aumentó hasta un 32\% (Mounk, 2018).

Estos datos son preocupantes. Permiten visualizar cómo la democracia está en crisis, la importancia de hacer algo para que los ciudadanos vuelvan a estar comprometidos con ella, que rechacen alternativas autoritarias y que los partidos políticos reflexionen acerca de la importancia de su sometimiento a las normas democráticas básicas. Para hallar soluciones a este problema, es fundamental que se indague acerca de los orígenes del apoyo a la democracia liberal, que, si bien ha sido una buena forma de gobierno, el autor es escéptico 
al pensar que esa ha sido la razón por la cual ha gozado históricamente de apoyo; si se busca en sus verdaderos orígenes nos permitirá encontrar las razones de porqué en la actualidad los ciudadanos de distintos países están desilusionados de la democracia liberal (Mounk, 2018).

\section{Capítulo II: Orígenes}

\subsection{Las redes sociales}

¿Las redes sociales son un peligro para la democracia liberal? En el último periodo de la edad media, que comprende los siglos XIV y $\mathrm{XV}$, la información escrita estaba al alcance de una élite selecta, pues para trasmitir ideas se requería de una persona que trascriba palabra por palabra el manuscrito original (Mounk, 2018).

Posteriormente, ya en el siglo XVI y XVII se dio paso a la alfabetización con la creación de la imprenta haciendo posible la comunicación de pocos a muchos. No obstante, quienes accedían a esta debían tener los recursos necesarios y el capital social suficiente para poder trasmitir sus ideas dando origen a los guardianes de la información, derivando, a su vez, en la difusión -únicamente- las posturas políticas y religiosas de las élites (Mounk, 2018).

En los últimos años, con la creación de la tecnología digital, especialmente las redes sociales, la comunicación se convirtió de muchos a demasiados $^{5}$, lo cual efectivamente permitió una mayor propagación y acceso a la información por parte de los ciudadanos de pie (Mounk, 2018).

Especialmente, el acceso a redes sociales, ha dado paso al activismo que realizan grupos histórica y estructuralmente segregados, dándoles la posibilidad de unir fuerzas y difundir sus argumentos en favor de que sus derechos sean reconocidos. Por el momento, observamos

5 Es decir, a diferencia de lo que ocurría en antaño, actualmente los medios de comunicación están al alcance de muchas personas y su difusión es a mayor escala. 
claros ejemplos de lo anteriormente mencionado como movimientos feministas, LGBTIQ, Black Lives Matter, entre otros. La comunicación en tiempos actuales efectivamente constituye una ventaja para quienes desean promulgar sus ideales a diferencia de décadas atrás donde movimientos como las sufragistas no contaron con la misma suerte, pues, para que su causa fuera escuchada tuvo que suscitarse la muerte de Emily Davison'.

No obstante, a pesar de estas diáfanas prerrogativas, las redes sociales han debilitado poco a poco la democracia liberal. Primero, menciona Mounk (2018) por la difusión de un discurso de odio caracterizado por su estilo incendiario más que por su veracidad, que para nada va acorde a los valores de libertad e igualdad. Segundo, porque ha servido como herramienta para que los populistas acaben con las normas democráticas básicas, por ejemplo, en el caso de las elecciones presidenciales de Estados Unidos en 2016. El ataque constante que Trump realizó a Clinton en redes sociales fue tal que un sondeo mostró que, en agosto de 2016, un $42 \%$ de los electores registrados habían llegado a creer que Clinton era maligna (Barrett, 2016).

Finalmente, Mounk (2018) considera que, "las redes sociales no son necesariamente buenas ni malas para la democracia liberal, lo cierto es que han contribuido a cerrar la brecha tecnológica entre quienes están dentro del sistema y quienes están fuera de él” (p. 152), lo cual ha servido para impedir el acaparamiento de los medios de comunicación que buscaban fijar un discurso político; cuestión que no quita el cuidado que se debe tener cuando esto es utilizado como herramienta por los populistas para acabar con normas democráticas básicas.

6 El 8 de junio de 1913, Emily se convirtió en mártir al interrumpir una carrera de caballos conocida como el Derby, pudo alzar su bandera sufragista y hacer visible el motivo por el cual luchaba con sus militantes: el derecho al voto de las mujeres. Este terrible suceso en la historia -uno de un sinnúmero de hechos-, nos muestra lo difícil que era para ciertos grupos sociales acceder a los medios de comunicación para difundir vulneraciones a sus derechos. Emily consiguió una victoria para las mujeres y esta historia quedó marcada en el corazón de muchas. 


\subsection{El estancamiento económico}

Mounk (2018) considera que existe un vínculo entre la situación económica y la estabilidad política. Cuando la democracia llegó a su época dorada o de mayor consolidación era porque varias personas eran partícipes de los beneficios del crecimiento económico del país en cuestión. Por esta razón, tenían confianza en los gobiernos de turno, dado que su estilo de vida se asemejaba mucho o alcanzaba incluso el valor de ser digno.

Al darse un estancamiento en la economía de un Estado, los ciudadanos pierden esa confianza hasta llegar al punto de creer que los políticos se han dejado llevar por intereses externos para redirigir los recursos; lo cual no es nada descabellado, especialmente en nuestra realidad ecuatoriana que cuenta con múltiples casos de corrupción7. Al surgir esta desconfianza, que según Mounk (2018), es mayor en aquellos ciudadanos que no han sufrido calamidades económicas y que, por tanto, tienen un temor al futuro que se muestra como incierto. La democracia cada vez va perdiendo sentido, pues los populistas, sean de extrema derecha o extrema izquierda, se aprovechan de la situación para presentar su oposición al statu quo, con soluciones simplistas que no tardan en caer al vacío. Pero, se pregunta Mounk (2018): ¿qué les hace falta a las democracias para prolongar su historial de estabilidad pasada?, ¿es suficiente con que un Estado democrático garantice una vida digna a sus ciudadanos?

\section{$2.3 \quad$ La identidad}

Lo que busca la democracia es que el pueblo tenga el poder, entonces, ¿quién es exactamente el pueblo? (Mounk, 2018). Esta interrogante planteada por el autor es fundamental. Abarca un factor que es

$7 \quad$ Para un análisis de los casos de corrupción en Ecuador desde el año 2008 hasta el año 2018 con relación a indicadores internacionales, véase: Cordovez, A., Ponce, J. y Rodriguez, A. (2019). Administración pública y corrupción en el Ecuador; un matrimonio inquebrantable. Revista mktDescubre, 250-257. DOI: 10.36779. 
determinante para entender las razones de por qué la democracia se está desconsolidando.

El autor a lo largo de este subcapítulo analiza cómo históricamente el pueblo no ha estado formado por todos sus habitantes. Desde Atenas el concepto de pueblo segregaba a mujeres y esclavos. Similar discriminación se dio en el Imperio Romano, Imperio Otomano y en la época anterior a la Segunda Guerra Mundial (Mounk, 2018).

Una vez con la experiencia del Holocausto, el fuerte nacionalismo y la homogeneidad que existía principalmente en las naciones de Europa Occidental se fue degradando hasta formar una democracia multiétnica, o al menos ese era el objetivo.

A diferencia de Estados Unidos, que no tenía el problema de la homogeneidad en su fundación, dado que fue un país creado a partir de colonias y siempre estuvo latente el ámbito de una democracia multiétnica. Empero, este ideal no siempre se cumplió dado los fuertes acontecimientos de discriminación racial lo largo de la historia, lo que conllevó a que la gente busque una democracia multiétnica pero que materialice la igualdad de las personas (Mounk, 2018).

Mounk (2018) hace mención a la ansiedad de los ciudadanos con respecto a la interrogante: ¿las democracias multiétnicas puedan ser viables en el futuro? Preocupación que ha brotado debido a la fuerte problemática de inmigración llevado a cabo a lo largo de la historia en Estados Unidos y en Europa Occidental con el conflicto suscitado en Siria. Este problema va de la mano con la ansiedad económica, agente que impulsa a muchos a una rebelión a favor del resurgimiento del nacionalismo y de la homogeneidad (Mounk, 2018).

Así es el escenario. Los populistas se han aprovechado de la situación para potencializar ese pánico infundado hacia el futuro con respecto a la seguridad y sustento de la población. De esta forma, han logrado alcanzar el poder, pues los electores han sido seducidos por las soluciones económicas simplistas de los populistas que, generalmente, han tenido la intención de echar la culpa a elementos externos de los problemas internos del Estado en cuestión (Mounk, 2018). 
El panorama está claro. Las democracias actuales no pueden garantizar un acelerado proceso en el incremento de nivel de vida de sus ciudadanos; los medios de comunicación hoy en día están a disposición de todas las personas; y la homogeneidad -como elemento para construir una democracia- ya no es primordial, dado que los Estados deben aprender a vivir en democracias mas iguales y diversas (Mounk, 2018).

\section{Capítulo tercero: remedios}

¿Cómo salvar a la democracia de su desconsolidación? El autor propone soluciones para que, en un futuro, la democracia liberal no se destruya. Un primer paso para alcanzar aquello es derrotar a los populistas en las urnas, con el afán de obtener dicha meta, el autor emite las siguientes reflexiones que se deben tomar en cuenta, lo cual considero es perfectamente aplicable a la realidad ecuatoriana:

- Primera lección: es importante mantener la unidad, no la división de la oposición (Mounk, 2018).

- Segunda lección: los partidos políticos que aspiran derrotar a los populistas deben conectarse con los intereses de los votantes mientras usan un lenguaje que permita dar cuenta que la oposición es parte del pueblo lo que conlleva a materializar sus necesidades (Mounk, 2018). En este punto, el autor hace énfasis en no caer en el discurso de los populistas, pese a esto, considero que traza una línea muy delgada. A lo largo del texto, explica básicamente las estrategias de los populistas, y, posteriormente -de forma bastante irónica- ofrece el uso de estas mismas herramientas como defensa para derrotar al mal primigenio, resultando ser entonces, populismo venciendo al populismo, cuestión que -aún con más ironía- no es inimaginable, ya que si los votantes no sienten agrado por la oposición van a seguir encantados con el partido populista.

- Tercera lección: es fundamental concentrarse en los aspectos positivos del populismo para poder abordar con mayor facilidad las soluciones, ya que permite el no estancamiento en los defectos (Mounk, 2018). 
- Cuarta lección: Mounk (2018) menciona que la oposición deberá mostrar su desencanto por el statu quo, dado que muchos de los cuales apoyan a partidos políticos populistas están desilusionados del mismo.

En definitiva, para alcanzar una democracia liberal más estable y defender los valores que esta promulga, es necesario tomar en cuenta aspectos estructurales, sociales, económicos y políticos, que, si bien han servido para dar origen al encanto por la democracia, asimismo han provocado la desilusión de esta.

\subsection{Domesticar el nacionalismo}

Como se señaló, el nacionalismo no siempre ha sido considerado un aspecto positivo para la democracia, a pesar de haber servido como elemento para que ésta se funde. Por todo lo vivido, es necesario que los Estados aprendan a convivir con la diversidad, procurando que no se vulnere la igualdad.

Sin embargo, en la actualidad se vive el resurgimiento de un nacionalismo excluyente (Mounk, 2018). El concepto de pueblo comienza una vez más a segregar a las minorías, lo que quiere decir que, como humanidad, nos vemos inmersos en un círculo vicioso, pues estamos regresando a aquello que en ataño juramos nunca retornar. No es que el pueblo ha olvidado, sino que este está ansioso por factores económicos y geográficos que deben ser tomados con pinzas por parte de los gobernantes si se desea mantener la democracia.

El retorno de este tipo de nacionalismo es defendido por políticos populistas como Trump, Wilders, o Le Pen. Lo que buscan es fundar en lo más intrínseco de los votantes el resentimiento social hacia las minorías étnicas o religiosas. Así, una vez con esta idea arraigada, presentarles lo que supondría la solución más acertada y fácil, pero lo cierto es que el problema no es tan simple como lo exponen. Cuando esto se manifieste será demasiado tarde, los populistas ya habrán socavado las instituciones democráticas. 
Domesticar al nacionalismo, no significa que no se tome en cuenta ciertos problemas que genera el elevado número de inmigración. Se puede optar por soluciones que no incentiven el odio o resentimiento social de cierto porcentaje de la sociedad; ejercer un mejor control fronterizo, tomando en cuenta que la nación es una circunscripción geográfica y que necesita ser tal para funcionar es una gran forma de ejemplificar este tipo de soluciones. Esto no quiere decir que se va a desproteger a los inmigrantes de tratos indebidos vulnerando sus derechos. En concreto, se trata de reafirmar la importancia de proteger a estas minorías, incluso, para la estabilidad económica, sin ignorar los temores de aquellos que se inclinan por gobiernos populistas con soluciones simplistas al problema de la inmigración.

\subsection{Arreglar la economía}

¿La ansiedad económica de los ciudadanos puede generar nostalgia de épocas pasadas? Por más sencilla que parezca la respuesta, la realidad es otra. Quedó claro que un componente que les impulsaba a los ciudadanos a creer en las democracias era el crecimiento en el nivel de vida. Efectivamente, si las personas están contentas con su estilo de vida, están estables, por lo que les interesa mantener el statu quo que les permite conservar esa situación.

En la actualidad, no podemos decir que la economía es la misma que hace décadas. La globalización ha traído consigo cambios que a muchas personas les ha obligado a salir de su zona de confort para acoplarse a una nueva realidad; más aún si consideramos la economía en tiempos de pandemia.

Hace poco, sin emergencia sanitaria, la situación no era del todo distinta. La crisis ya empezó a manifestarse en muchos países; siendo la pandemia un conducto que mostró -para bien o para mal-, de manera diáfana, los aprietos en los que se encontraban muchos Estados. Un componente importante dentro de este contexto fue el desarrollo de la economía digital la cual avanza de manera acelerada, mientras que los seres humanos nos movemos a paso lento; ocasionando nostalgia y ansiedad, por aquellas épocas en donde la 
estabilidad económica era una realidad, o al menos, a la mira de la población promedio, alcanzable.

Y el populismo asecha una vez más, pero ahora lo hace con la herramienta de la tan nombrada nostalgia, hoy ya no es necesaria la universalización del concepto de este término, dado que los partidos políticos son tan astutos que dejan a la imaginación y al sentimiento de cada persona, tanto la definición como la forma de manifestación de esta.

El autor, en este punto, identifica los factores económicos que influyen al deceso de la democracia liberal. Entre estos, encontramos a la vivienda que debe ser fundamentalmente garantizada para que los ciudadanos no sientan temor al futuro, miedo que muchas veces es sobredimensionado.

Mounk (2018), plantea que, para garantizar aquello, debería considerarse la restructuración de la política de vivienda, de tal forma que las personas en realidad crean que pueden acceder a una vivienda digna, desvaneciendo su temor a un futuro infortunado.

De igual manera, bosqueja una reconfiguración de la política fiscal. Por cuestiones obvias, esta influye directamente en la redistribución de las riquezas (Mounk, 2018). Es decir, se trata de materializar el principio de capacidad contributiva asegurando que las personas paguen según sus condiciones.

Personalmente, estimo que este cambio expuesto por el autor supone una erogación fuerte por parte del Estado con ciertos matices, pues la consideración de que todos los derechos económicos y sociales son prestacionales quedó desvirtuada'. Es complejo, aún para un país de

8 Al respecto véase: Sunstein, C. (2018). Las cuentas pendientes del sueño americano: por qué los derechos sociales y económicos son más necesarios que nunca. Buenos Aires, Argentina: Siglo Veintiuno Editores

Argentina S.A. Y, Pisarello, G. (2007). Los derechos sociales y sus garantías. Elementos para una reconstrucción. Madrid, España: Editorial Trotta, S.A.

Autores que consideran que no se debería catalogar a los derechos económicos y so- 
primer mundo, asegurar a absolutamente toda su población una vida o vivienda digna. Por esta razón, muchos países se cuidan de garantizar estos derechos a través de normas de aplicación directa, inclinándose a su regulación mediante normas pragmáticas, lo cual, en cierta forma, les convierte en consecuencialistas, pues tienen claro el gasto que puede generar aquello (Guastini, 2003; Sunstein, 2017).

Con esto no quiero decir que por complicado que resulte para el Estado garantizar ciertos derechos económicos y sociales, deben dejar de realizarlo. De hecho, deben hacerlo. Es parte de su obligación para con sus ciudadanos, para con el pueblo que les otorgó su poder. No obstante, resulta ineficiente dejar dicha posición a medias, agrego entonces que para hacerlo deben tomar en cuenta la reflexión que he manifestado con anterioridad: el aparato Estatal debe tener sumamente claro cómo garantizar estos derechos, además del tipo de norma con el que pretenderán ejecutarlos. En definitiva, sí, calmar la ansiedad económica del pueblo puede llevar a que se vean desencantados por partidos políticos populistas que utilizan su nostalgia como una artimaña para sus propios fines.

\subsection{Renovar la fe cívica}

¿Renovar la fe cívica ayudará a que los ciudadanos vuelvan a confiar en los políticos? Hoy en día vivimos en una época digital, donde acceder a todo tipo de información es sencillo y fácil; además, se ha dado una modificación en la naturaleza de la comunicación a causa del amplio alcance de las redes sociales.

La tecnología facilita a que las personas en cuestión de segundos accedan a datos que definen el valor cívico, lo cual nos lleva a creer que nos encontramos frente a una ventaja inminente. La cuestión no es así del todo. Este acceso inmediato ha ocasionado que varias

ciales como esencialmente prestacionales. Esto, generalmente, instaura la creencia de que es casi imposible garantizarlos y judicializarlos, ya que muchos de los derechos civiles y políticos, de igual forma, suponen una erogación por parte del Estado. 
personas no se preocupen por los mencionados datos, o de plano, se desentiendan de la política. El tema de la fe cívica se encuentra solamente a un click, más no en las mentes de los ciudadanos.

Por lo tanto, lo que se necesita, según Mounk (2018), es un reforzamiento de la fe cívica, de tal forma que a través de la educación se enseñe lo positivo de vivir en una democracia liberal, e incluso sus aspectos negativos, anhelando que las personas apoyen lo primero y sean conscientes sobre lo segundo. Si las personas tienen suficiente confianza será fácil que se enfoquen en el primer camino sin desconocer los aspectos nocivos con el fin de solventarlos.

Para reforzar esta confianza se requiere poner un alto al desenfreno de información -si así puede llamarse- sin fuentes fidedignas que circulan por redes sociales. El discurso de odio que se fomenta en estos espacios solamente ocasiona que la desconfianza aumente; las personas están saturadas por teorías conspirativas que muestran como la política, y en general, el statu quo, ya no funciona (Mounk, 2018).

No se trata de censurar, porque de esa forma estaríamos vulnerando el tan aclamado derecho a la libertad de expresión. Lo que sí se podría realizar es exigir a las grandes empresas la mejora de los algoritmos con la finalidad de evitar, en lo posible, el mayor número de noticias falsas (Mounk, 2018).

En sí, se trata de criar ciudadanos que fortalezcan la fe cívica desde que son infantes, para que cuando crezcan, después de ejercer el correspondiente discernimiento, se inclinen por la democracia liberal, propendiendo a la unión entre libertad y derechos individuales. 


\section{Conclusiones}

¿La era digital ha desencadenado una crisis que nos lleve a pensar que las democracias de diferentes países se están desconsolidando? Parece ser que la respuesta, al menos de forma indirecta, es afirmativa, pero el escenario no es del todo pesimista. A lo que me refiero, es que, como bien analiza el autor, la tecnología -y en especial las redes sociales- han potencializado elementos políticos, económicos y sociales que ponen en riesgo la democracia.

Lo que nos lleva a concluir que el problema no es reciente, más bien de índole estructural. La tecnología de la información y comunicación ha traído complicaciones. Principalmente, lo que hizo fue exteriorizar y manifestar de forma vehemente las frustraciones y resentimientos que ya sentían varias personas mucho antes del surgimiento de las redes sociales.

Los partidos políticos populistas no han perdido el tiempo y han sacado provecho de esta situación. Se han gorroneado de los agentes ya existentes que estaban causando malestar a la gente. Han utilizado las redes sociales como instrumento para difundir temores, miedos y discursos de odio; dirigiéndonos a una crisis en donde la democracia liberal pende de un hilo.

El auge del populismo puede llevar a que un hombre fuerte alcance el poder gracias a su discurso centrado en que solo él es el único vocero del pueblo. Como consecuencia la población cada vez se siente más ajena a las decisiones tomadas por los políticos, es decir, se ha caído en un liberalismo no democrático. Entonces, una vez en el poder, la perorata populista con la cual presumían ser los mejores representantes de la voluntad popular cae por completo cuando empiezan a socavar instituciones democráticas hasta acabar inmersos en un gobierno autoritario.

He ahí la importancia de tener en cuenta las reflexiones y diversas soluciones para hacer frente a gobiernos populares que al autor desarrolla a lo largo del libro: evitar que la era de los Estados democráticos terminen siendo un recuerdo plasmado únicamente en los 
libros de historia. El tema no es sencillo. Para poder enfrentarlo es fundamental que las personas vuelvan a tener interés en la política, así se podrá analizar las razones por las cuales muchas personas se han desilusionado de la democracia liberal, directrices que nos mostrará el camino para seguir la vía que nos llevará a la atenuación de dicho desconforme.

Por último, pero no por ello menos importante, se formula la siguiente reflexión. ¿Es posible que el ser humano, para la búsqueda de su felicidad y bienestar, se desprenda totalmente de cosas externas? Para los estoicos la respuesta fue claramente afirmativa. Según su filosofía, de eso se trata el vivir bien. Alejarse de intereses externos implica que una persona se convierta en un ser tranquilo y estable sin depender de nadie más que de sí mismo, sin esperar favores ni fortuna de otros (Parra, 2000).

Ojalá así realmente fuera la vida. Desprenderse de todo lo que nos rodea efectivamente puede llevarnos al punto de no sentir dolor y por consiguiente alcanzar la felicidad. Pero hacer eso puede provocar que nos alejemos de manera irremediable de la realidad, y cuando estemos consientes de aquello, la frustración va a ser tan grande que por ningún motivo vamos a estar cerca de conseguir la felicidad de la que tanto hablaron los estoicos.

Aquí surge la sintaxis y la lógica del ser sociable por naturaleza. Indudablemente, no podemos ser indiferentes ante los conflictos que enfrenta un Estado democrático. El pretender no sentir nada al respecto solo nos va a traer frustraciones. Si renunciamos a la indignación, ira e impotencia que generalmente sentimos frente a casos de corrupción, partidos políticos populistas, democracias iliberales, minorías segregadas, etc., únicamente nos transformará en meros espectadores de un Estado que se desmoronará de poco a poco, hasta que la lucha por nuestras convicciones quede totalmente sepultada debajo de un cúmulo de bloques de populismo. 


\section{Referencias Bibliográficas}

Barrett, J. (29 de agosto de 2016). Poll: Who's More “Evil”, Hillary or Trump? Daily Wire. Recuperado de www.dailywire.com/news/8720/

Guastini, R. Constitucionalización del ordenamiento jurídico: caso italiano, en: Carbonell, M. (coord.). (2003). Neoconstitucionalismo(s). España: Editorial Trotta, S.A.

Müller, J. (27 de enero de 2016). The Problema with Democracy. Social Europe. Recuperado de www.socialeurope.eu/2016/01/the-problem-with-iliberal-democracy

Mounk, Y. (2018). El pueblo contra la democracia: por qué nuestra libertad está en peligro y cómo salvarla. Barcelona, España: Editorial Paidós.

Parra, C. (2000). La filosofía y el sabio estoico: Examen de la virtud. Revista Horizontes ducacionales, (5), 27-35. Recuperado de http://www. redalyc.org/articulo.oa? $=97917880004$

Sunstein, C. (2018). Las cuentas pendientes del sueño americano: por qué los derechos sociales y económicos son más necesarios que nunca. Buenos Aires, Argentina: Siglo Veintiuno Editores Argentina S.A.

Uprimny, R. (2001). Legitimidad y conveniencia del control constitucional de la economía. Precedente Revista Jurídica, (-) 35-66. DOI: 10.18046/ prec.v0.1382

Waldron, J. (1998). Judicial Review and the conditions of democracy. Journal of Political Philosophy, 6(4), 335-355. DOI: 10.1111/14679760.00058 .

\section{Jurisprudencia Constitucional}

Corte Constitucional del Ecuador. Sentencia No. 024-16-SIN-CC. Caso No. 0013-13-IN de 6 de abril de 2016. Jueza ponente: Wendy Molina Andrade. 